\title{
Understanding Mentor NeEdS IN ONLINE ENGINEERING OUTREACH
}

\author{
Katherine Dornian, Dr. Mohammad Moshirpour, and Dr. Laleh Behjat \\ University of Calgary \\ katherine.dornian@ucalgary.ca, mmoshirp@ucalgary.ca, laleh@ucalgary.ca
}

\begin{abstract}
Mentoring in engineering outreach is being adopted more and more by university programs that aim to increase diversity in their school. It is fair to say that mentoring can be a useful tool to do this, but not always. Mentor training can help improve program outcomes (attendance, engagement, retention). In this study, we look at one case of a virtual engineering outreach program, find the challenges, and make recommendations for mentor training modules that could address challenges. In doing so, we believe that this sets a foundation for building training for many mentor-based virtual outreach programs in engineering.
\end{abstract}

Keywords: outreach recruitment, mentoring, digital skills, competencies

\section{INTRODUCTION}

Improving diversity is of critical importance for the Canadian engineering profession. Within the computerrelated engineering fields, diverse gender and ethnocultural representation falls behind other science disciplines and is significantly behind parity with the Canadian population $[1,2]$. Diversity will be essential to finding innovative solutions to the world's challenges in this century $[3,4]$. Mentoring is one promising strategy for improving diversity $[5,6]$.

In this paper, we begin by discussing the importance of well-trained mentors in engineering outreach programs that recruit for diversity. Following that, the study finds the needs of mentors in one such virtual outreach program. The results isolate the main themes in the data collected and refer these back to mentorship literature to make guidelines for mentor training that would improve the mentoring practice. Finally, the significance of these results to the broader community practicing engineering outreach will lead us to the conclusion.

\section{BACKGROUND}

The Schulich Ignite program at the University of Calgary uses mentoring relationships as part of its outreach strategy to promote underrepresented groups to find their potential as engineers and to inspire individuals in these groups to enroll in engineering [7]. In this eight-session, out-of-school program, undergraduate engineering mentors teach a group of youth (mentees aged 15-18) programming skills, like what they might find in engineering. The program culminates in mentees creating a project, such as a computer game, and receiving a certificate. Since 2017 , the program ran on the university campus. It moved online in the Spring of 2020 due to COVID-19-related lockdowns, and the plan is to remain online for the foreseeable future. Mentoring remains a vital component of the program in this shift to virtual delivery, creating new challenges and opportunities.

\subsection{Engineering Outreach for Improving Diversity}

Mentoring and outreach help attract and retain students from underrepresented groups within engineering [8]. Outreach programs can support K-12 education by providing tools and resources to educators. In return, outreach programs and their institutions benefit by attracting more students. University outreach and mentoring programs both benefit from the availability of student volunteers. Student volunteers are interested in improving their professional and technical skills and can often benefit from volunteering by receiving course credits or other honours proffered by the institution [9-11]. In mentoring opportunities some reasons that students enrolled was because they were interested in influencing the next generation, enjoy teaching [12], or wanted to develop specific skills [13]. Other motives such as selfenhancement and intrinsic satisfaction may also play a role [14].

\subsection{Mentoring Diverse Youth}

Mentoring is a broadly used strategy in organizations to promote individuals' positive development $[15,16]$. In this paper, we refer to mentoring as an activity where a mentor offers guidance and support to a younger person, usually through building an emotional connection between a mentor and a mentee [15]. While the implementation and results of youth mentoring programs differ and can be challenging to measure, mentoring has some generally 
accepted positive outcomes, including improving attitudes, physical health, and academic grades in mentees [17]. Mentoring has been used to achieve these outcomes with students in underrepresented groups such as women, Black, Indigenous, Hispanic, and persons with disabilities (among others) $[6,18]$. It is worth noting that mentoring relationships can help achieve positive outcomes even when identities like race and gender are not matched [17, 19]. Furthermore, benefits extend beyond mentees; Undergraduate mentors are likely to experience improved academic performance, better personal skills, and higher retention rates $[13,20]$.

Mekinda and Hirsch published "A Revised Framework for Investigating Mentoring Relationships in After-School Programs" [21, 22]. The Framework details individual, environmental, and mentoring relationship characteristics that lead to program experiences (attendance, engagement, retention) and outcomes for both mentor and mentee. Individual characteristics speak to the identity and attitudes of both mentees and mentors. Environmental characteristics pertain to activities and organizational practices that shape the mentor-mentee interaction. Also, in the Framework, characteristics of mentoring relationships are broken into two categories of mentoring arrangements and mentoring behaviours. The former breaks down arrangements as either individual, group, collective, trilevel, or reciprocal. The latter list includes behaviours performed in the relationship such as emotional support, guidance/teaching, sponsorship/advocacy, and learning/collaboration.

The Framework by Mekinda and Hirsch has similarities to Rhodes' "Conceptual Model of Youth Mentoring" [23] but supplements Rhodes' Model with factors pertinent to the investigation of after-school programs. Rhodes focuses on factors of mentoring that assist the mentee's development in three ways: (1) social and emotional wellbeing, (2) cognitive development and (3) role modelling. In the Model, these developmental characteristics result in positive outcomes (e.g. academic performance, social competence) when mediated through a personal connection with a mentor.

\subsection{Mentor Training Programs}

It is vital to note that a mentoring practice alone is not enough to create positive outcomes. Some mentoring relationships have negative consequences, for instance, when they are planned haphazardly or fail to get willing commitment [17, 24]. Mentor training is not explicitly part of the Framework and Model above, but it can contribute to programs' successes, even though it is not widely practiced [23]. Several science and engineering outreach programs have training programs for mentors. Mentor training modules cover lessons such as learning about specific activities or subject areas [11-13,25], guidance on educational practices $[12,13,25,26]$, creating inclusive environments [8, 12, 27], developing competencies [11, 26, $28]$, and more, including combinations of these modules.

\subsection{Mentoring in the Schulich Ignite Program}

Mentoring is a pivotal part of the Schulich Ignite program, as detailed in previous papers [7]. To summarize, each mentor assists approximately one to six mentees in completing coding exercises and their final project. Mentors are typically undergraduate engineering students from the University and bring a range of skills and experiences to the mentoring practice. Before each workshop, the Schulich Ignite leadership team conducts interviews with students interested in becoming mentors to screen for competence and ability.

The Schulich Ignite program has provided some training to mentors over the years. In 2017, diversity training happened before the program. In subsequent iterations, training was focused on an orientation to the program's tools and getting to know other mentors [7].

Given the existence of mentoring in the Schulich Ignite program, the desire to improve outcomes (such as increasing participation of diverse students), and new challenges created by virtual learning, this study's focus is on recommendations for mentor training tools that support mentors so that they can best support mentees. To best design training tools, this study sets out to understand the challenges as seen by the mentors in the virtual environment. From this understanding, we'll make suggestions for mentor-training tools that could improve such mentoring relationships.

RQ1: What are the challenges mentors face in a virtual engineering outreach program?

RQ2: How do the program and mentors' needs fit within existing mentoring theories?

RQ3: What do these needs and their relation to mentoring frameworks tell us about the design of mentortraining tools?

\section{METHODOLOGY}

Data were collected from focus groups, debrief artifacts and field notes of the Fall 2020 term of the Schulich Ignite program. Two virtual focus groups with six mentors were conducted following the program's conclusion (150 minutes of recordings). Participating mentors represented different lengths of involvement and different menteementor arrangements (one-to-one and group-to-one). In the focus group, participants were encouraged to discuss their role as mentors, accomplishments, challenges faced, and needs. Recordings of the focus groups were transcribed.

Debrief artifacts were also collected. The debrief documents were filled in by most mentors at the end of each Schulich Ignite session. The documents contain what mentors recorded as going well, what didn't, and some responses to program leader questions. 
An interpretive research methodology has been applied to understand the qualitative data collected [29]. Data were collected, coded, and analyzed using a thematic analysis approach [30, 31].

Coding and thematic analysis were then conducted using an inductive approach [31] to avoid over-sensitivity to the mentoring theories to which we would later compare with the results. First, all data were reviewed, and each line was given a code that summarized the described experience in the transcript. This resulted in 405 codes. After that, codes were collected into themes (22 themes were initially found), which were then condensed into the final themes presented in the results. The final themes were verified against the original data to ensure accuracy and completeness.

\section{RESUltS}

Our findings indicate four broad themes that most affect mentors: (1) Teaching, (2) role modelling, (3) emotional environment, and (4) virtual space. Under each theme, the challenges that emerged are enumerated.

\subsection{Teaching}

Mentors primarily see their role as teachers. Teaching includes explaining, simplifying, showing examples, and answering questions about coding. These functions are primarily instrumental and factual, where the mentor sees themselves as passing down knowledge. Teaching roles appear to have the most positive associations and confidence. For example, one mentor in the focus group described accomplishment after explaining how loops worked and having the student understand. The mentors struggled most with adapting material to different learners, although they recognized this as a great opportunity.

To summarize, the challenges in teaching that the mentor's faced are:

- C1: Assessing mentee's knowledge and understanding

- C2: Understanding the mentee's learning style

- C3: Explaining difficult and abstract concepts in concrete ways

- C4: Prioritizing and addressing multiple different needs in a limited time

Recognizing these challenges shows an awareness of the mentoring relationship as serving a function of guidance/teaching and cognitive development seen in Mekinda and Hirsch's Framework and Rhodes' Model, respectively. As per Rhodes' research [23], mentors could extend cognitive development by providing students with opportunities to reflect and think critically about their learning in the program. In doing so, the challenge of understanding a mentee's learning style could be resolved.

\subsection{Role Modelling}

Mentors recognized the importance of engaging, encouraging, helping, guiding, and motivating mentees. Role modelling was where the mentors stepped back from delivering knowledge and supported the learner's exploration. For instance, one mentor explained how he helped break down and simplify his mentee's idea of creating a solar system simulation to an appropriate level for his mentee to accomplish and avoid discouragement.

Improving the engagement was most mentioned in the role modelling theme. While mentors felt confident in their ability to help students through a challenge, they were aware that some mentees would "lose focus" when they did not get it and not ask for help.

Mentors also pointed out the importance of "sparking that passion," as one mentor described it. The mentor described both bringing passion to the lessons and making the mentees interested in the content. Furthermore, mentors discussed how connecting coding to existing interests was helpful.

Overall, two more challenges emerged from role modelling:

- C5: Finding mentee's interests

- C6: Knowing when the mentee encounters a challenge

Role modelling is an integral part of Rhodes' Model. These discussions speak to the mentor's awareness of being someone with experience and recognizing the mentee bringing their interests (although they sometimes struggled to find what).

\subsection{Emotional Environment}

Although rarely mentioned, mentors implied an awareness of the benefits of having a positive emotional environment. Such an environment meant that the mentees were comfortable and confident, leading to benefits like mentees engaging with more questions. However, the mentors did not speak much to their practices of creating this environment themselves, instead attributing the emotional environment's tone to factors beyond their control, such as students being friends outside of the program or that a mentee lacked confidence. On the other hand, the mentors did see their role in encouraging and, notably, not discouraging mentees. Their solution to this often fell to teaching techniques such as simplifying concepts useful to a mentee.

Mentors also noted their own emotional needs, noting that the lack of engagement meant they rarely received thanks or feedback about how they were doing.

These results point to the following challenges mentors face:

- C7: Understanding the challenges mentees are facing

- C8: Receiving and delivering feedback for mentors

The emotional environment is foundational in Rhodes' Model, where development and positive outcomes are 
mediated through a personal connection built on mutuality, trust, and empathy. In observations of the Fall 2020 program, there was limited time to build this connection before lessons started. Mekinda and Hirsch include emotional support as a mentoring behaviour. We would thus suggest one more challenge the mentors face:

- C9: Building rapport between the mentor and mentee

\subsection{Virtual Space}

Environmental factors of virtual learning also pose challenges for the mentors. These are factors created by the technology and tools used. The mentors demonstrated exceptional skills in adapting and responding to challenges presented in the new virtual space. However, technical challenges and bugs were not helpful. Furthermore, other challenges presented were distractions (either on the computer or at home), long response times, private chat between mentees, and not seeing the mentee's code. Screen sharing was repeatedly mentioned as a great asset so that mentors could, for example, catch syntax and spelling mistakes.

In the set-up of the virtual space, mentors were on their own to work with mentees. One mentor described it as "everyone was kind of isolated in their own breakout rooms." Moreover, other mentors spoke to the benefits of mentoring in person and having other mentors nearby to help.

Thus, the virtual space presented three challenges:

- C10: Seeing what mentee is working on

- C11: Knowing when the mentee has lost attention

- C12: Creating ways to collaborate between mentors

The physical, let alone virtual, spaces in which mentoring occurs are notably left out of much of the literature reviewed for this paper. Although Mekinda and Hirsch include environmental characteristics, this covers organizational structures and practices, activities, partnerships, family, and the social community environment.

\section{DISCUSSION}

Our research finds twelve challenges faced by mentors in a virtual engineering outreach program (C1-C12), which addresses our first research question. These challenges span four themes: teaching, role modelling, emotional environment and virtual space. Within these themes, the challenges presented by the virtual space are distinctly more challenging in virtual outreach. Challenges related to role modelling and emotional environment are somewhat heightened by the virtual space but are present in nonvirtual mentoring spaces as well. For instance, virtual communication makes getting to know the mentee and other mentors more challenging because interaction is not facilitated by a natural physical presence. However, even non-virtual mentor-mentee pairs struggle to build rapport.
Challenges related to teaching span virtual and non-virtual outreach activities.

By comparing our observational and interview data to existing theories to address the second research question, we see a close but not perfect fit. Notably, mentors seemed less aware of their ability to influence the emotional environment and the literature we used lacked a description of the mentoring spaces. We also noted that the mentoring theory we used did not make many recommendations for mentor training.

The omission of mentoring spaces is particularly interesting in a program like Schulich Ignite that teaches computer programming. Physical and virtual spaces have always been a factor in this program's operation, given the need for access to computers. Furthermore, it had been noted that the university's physical location created barriers for some students to benefit from the program before it moved virtually [7]. Nonetheless, several similarities emerged that highlighted the mentoring behaviours and other factors that contribute to the program's positive outcomes.

\subsection{Mentor Training}

Given the challenges recognized and the success found in other engineering outreach literature, we can make some broad recommendations for mentor training in virtual engineering outreach. Given that some of these challenges are present in non-virtual outreach environments, we believe these recommendations could support more than just virtual outreach.

Given the importance of a strong connection between mentor and mentee, helping mentors build rapport (C9) should be prioritized. This sort of training would be most beneficial before the start of the workshop and could easily include lessons on finding shared interests (C5), understanding the mentee's learning style (C2), how to assess mentee's knowledge (C1), and how to solicit feedback (C8). In order to address identity differences or biases, inclusivity training like that in [8], [12], and [27] could be explored.

A module on competencies covering collaboration and teamwork could help break down feelings of isolation (C12) and address challenges with prioritizing multiple different needs (C4). This sort of module could also include lessons about delivering and receiving feedback (C8) between mentors so that the mentoring itself becomes a learning tool, similar to the concept of "teaching squares" [32]. Such a module would fit nicely with building rapport at the start of the program.

A training module covering educational practices would benefit mentors struggling to explain abstract concepts (C3) and understand the challenges mentees face (C7). Educational practices could also add to lessons on learning styles (C2) and support the mentor's ability to assess knowledge and understanding $(\mathrm{C} 1)$. These lessons could be delivered throughout the program to maintain relevance (as 
in the BEAM program model [25]). Since not all mentors seem to face this challenge similarly, the lessons could also be available on an as-needed basis.

\subsection{Other Mentor Tools}

Some of the mentors' challenges cannot be solved by training alone, and some of the challenges may change once training is implemented. For instance, a better rapport could improve engagement challenges like knowing when a challenge has been encountered by the mentee (C6), knowing when attention has been lost (C11) or improving the mentee's comfort with sharing screens (C10). However, these challenges also pose an opportunity for the design of virtual environments and virtual platforms. These opportunities are vast but hint at learning tools that can alert a mentor to code problems or maximize collaborative coding spaces.

\subsection{Limitations}

As is the case with human-based research, the data capture a mere snapshot in time representing the people and conditions present. Still, the findings are generalized to theorize about the needs of mentors in virtual learning environments. Further research is needed to continue to validate the findings and test the recommendations.

With qualitative thematic analysis, we also recognize that as researchers, we have played an active role in constructing the themes found through the methods and data [33].

\subsection{Future Research}

While not the focus of this research study, it is worth noting that there were occasions that mentors in the focus groups alluded to engineering concepts to describe their mentoring practice. Besides the computing essentials (which one might expect to be mentioned when discussing an introductory computer programming workshop), mentors exhibited awareness of concepts like problem complexity, presentation skills, problem decomposition, abstraction, and trade-offs. While not mentioned extensively, it would be worth investigating engineering attributes and software engineering knowledge in the mentors. Furthermore, mentor training could be designed in a way that supports these competencies and knowledge areas.

The virtual environment posed many challenges for educators in 2020, and after-school programs experienced the same difficulties. Overall, the theories we found fit moderately well, even providing insights for other areas of exploration. However, it seems beneficial for more research to be done on mentorship frameworks that incorporate the impacts of the physical or virtual spaces in which mentoring happens.
The mentor training itself still requires implementation and research to measure the effects such training has on diversity in the program.

\section{CONCLUSION}

Like many educators in 2020, engineering mentors have faced challenges with the virtual environment. We have identified several of these challenges and found opportunities to create training and tools to address them using youth-mentoring theories. Good mentors have the opportunity to affect the lives and experiences of diverse youth. Training is a crucial step to helping mentors find their strengths. We have suggested three training modules (building rapport, professional competencies, and educational practices) and a platform improvement that could help mentors. With more research, we hope to implement this training and find its effects in the future.

\section{Acknowledgements}

This study was approved by the Conjoint Faculties Research Ethics Board at the University of Calgary

We acknowledge that the Schulich Ignite program receives funding support from the Government of Canada; Innovation, Science, and Industry; CanCode Initiative, IEEE Women in Engineering Southern Alberta Section, and the Schulich School of Engineering.

\section{References}

[1] M. Domsy and A. Rodrigues, "Canadian Engineers for Tomorrow: Trends in Engineering Enrolment and Degrees Awarded 2014-2018," Engineers Canada, 2020. Accessed: 17 May 2020. [Online]. Available: https://engineerscanada.ca/publications/canadianengineers-for-tomorrow-2018\#trends-in-engineeringenrolment-and-degrees-awarded-

[2] Engineers Canada. "2018 National Membership Information."

https://engineerscanada.ca/reports/nationalmembership-report/2018-report (accessed 17 May 2020).

[3] C. R. Østergaard, B. Timmermans, and K. Kristinsson, "Does a different view create something new? The effect of employee diversity on innovation," Research Policy, vol. 40, no. 3, pp. 500-509, 2011, doi: 10.1016/j.respol.2010.11.004.

[4] D. E. Chubin, G. S. May, and E. L. Babco, "Diversifying the engineering workforce," J. of Eng. Educ., vol. 94, no. 1, pp. 73-86, 2005.

[5] K. Atkins, B. M. Dougan, M. S. Dromgold-Sermen, H. Potter, V. Sathy, and A. T. Panter, "'Looking at Myself in the Future": how mentoring shapes scientific identity for STEM students from underrepresented groups," Int. 
J. STEM Educ., vol. 7, no. 1, p. 42, 2020, doi: 10.1186/s40594-020-00242-3.

[6] W. C. L. Jr. and K. J. Cross, "Help Me Help You: Building a Support Network for Minority Engineering Students," presented at the 120th ASEE Annual Conference \& Exposition, Atlanta, USA, 2013.

[7] K. Dornian, M. Moshirpour, and L. Behjat, "Description of pre-university coding workshops recruiting for diversity," Proc. of the Canadian Eng. Educ. Assoc. (CEEA), pp. 1-8, 2020 June 12, doi: https://doi.org/10.24908/pceea.vi0.14152.

[8] C. Gartland, H. Hawthorne, and C. M. McLoughlin, "Discourses, identities and learning: implications for the training of student ambassadors in engineering," presented at the Inspiring the next generation of engineers Engineering Education, 2010.

[9] M. Schulte et al., "National Society of Black Engineers Community Outreach Program," presented at the 29th ASEE/IEEE Frontiers in Education Conference, San Juan, Puerto Rico, 10-13 November 1999.

[10] M. Lander, "Technology Based Mentoring; working with the Imagineering Organisation to develop professional skills through engaging with STEM based outreach activity.," presented at the Innovation, Practice and Research in Engineering Education EE2012, 2012.

[11] D. Knight, L. Hinojosa, J. Poleman, and M. Hannigan, "An air quality inquiry: A curricular approach to preparing student mentors of air quality research projects in rural schools " in 8th Research in Engineering Education Symposium (REES 2019), Cape Town, South Africa, B. Kloot, Ed., 10-12 July 2019, pp. 761-770.

[12] R. S. Lewis et al., "Examining the Value of Mentoring in Youth Engineering Programs: What Motivates a Mentor to Mentor?," presented at the 2018 IEEE Frontiers in Education Conference (FIE), San Jose, USA, 2018.

[13] Y. B. Kafai et al., "A Cascading Mentoring Pedagogy in a CS Service Learning Course to Broaden Participation and Perceptions," in SIGCSE'13, Denver, USA, 6-9 March 2013.

[14] T. D. Allen, "Mentoring others: A dispositional and motivational approach," Journal of Vocational Behavior, vol. 62, no. 1, pp. 134-154, 2003, doi: 10.1016/s0001-8791(02)00046-5.

[15] D. L. DuBois and M. J. Karcher., "Youth mentoring in contemporary perspective," in The handbook of youth mentoring, D. L. DuBois and M. J. Karcher. Eds., 2 ed. USA: SAGE Publications, Inc., 2014, pp. 3-13.

[16] K. Hobson and Z. W. Taylor, "Mentoring.ca: types of mentoring programs featured on Canadian postsecondary education websites," International Journal of Mentoring and Coaching in Education, vol. 9, no. 3, pp. 279-290, 2020, doi: 10.1108/ijmce-092019-0089.
[17] D. L. DuBois, N. Portillo, J. E. Rhodes, N. Silverthorn, and J. C. Valentine, "How effective are mentoring programs for youth? A systematic assessment of the evidence," Psychol Sci Public Interest, vol. 12, no. 2, pp. 57-91, Aug 2011, doi: $10.1177 / 1529100611414806$.

[18] L. Tsui, "Effective Strategies to Increase Diversity in STEM Fields: A Review of the Research Literature," he Journal of Negro Education, vol. 76, no. 4, pp. 555-581, 2007.

[19] B. R. Ragins, "Antecedents of diversified mentoring relationships," Journal of Vocational Behaviour, vol. 51, pp. 90-109, 1997.

[20] J. M. Good, G. Halpin, and G. Halpin, "A Promising Prospect for Minority Retention: Students Becoming Peer Mentors," The Journal of Negro Education, vol. 69, no. 4, pp. 375-383, 2000.

[21] M. A. Mekinda and B. J. Hirsch, "After-school programs," in Handbook of youth mentoring, D. L. Dubois and M. J. Karcher Eds., 2 ed. USA: SAGE Publications, Inc., 2014, ch. 15, pp. 221-232.

[22] B. J. Hirsch and V. Wong, "After-school programs," in Handbook of youth mentoring, D. L. Dubois and M. J. Karcher Eds.: Sage Publications, 2005, ch. 24, pp. 364375.

[23] J. E. Rhodes, Stand by Me : The Risks and Rewards of Mentoring Today's Youth. Harvard University Press, 2004.

[24] P. A. Vesilind, "Mentoring Engineering Students: Turning Pebbles into Diamonds," Journal of Engineering Education, vol. 90, no. 3, pp. 407-411, 2001.

[25] A. Almaguer, R. Tangsombatvisit, M. Ford, S. Y. Chen, L. A. Pruitt, and N. Ray, "Building engineers and mentors: A model for student-led engineering outreach," 2011.

[26] J. DeWaters, S. Powers, and M. Graham, "Partners in engineering: Outreach efforts provide holistic engineering education for middle school girls," presented at the American Society for Engineering Education, 2006.

[27] C. Pfund, C. M. Pribbenow, J. Branchaw, S. M. Lauffer, and J. Handelsman, "The merits of training mentors," Science-New York Then Washington, vol. 311, no. 5760, pp. 473-474, 2006.

[28] B.-M. Block and A. Georgiadis, "Project-Mentoring in Engineering Education - a competence-oriented teaching and learning approach," presented at the Proceedings of the 2012 IEEE Global Engineering Education Conference (EDUCON), 2012.

[29] A. Johri, "Conducting Interpretive Research in Engineering Education Using Qualitative and Ethnographic Methods," in Cambridge Handbook of Engineering Education Research, ch. 28, pp. 551-570. 
[30] V. Braun and V. Clarke, "Using thematic analysis in psychology," Qualitative Research in Psychology, no. 3, pp. 77-101, 2006.

[31] R. E. Boyatzis, Transforming qualitative information: Thematic analysis and code development. sage, 1998.

[32] N. Haave, "Teaching squares: A teaching development tool," Teaching Professor, vol. 28, no. 1, 2014.

[33] G. W. Taylor and J. M. Ussher, "Making Sense of S\&M: A Discourse Analytic Account," Sexualities, vol. 4, no. 3, pp. 293-314, 2001. 